\title{
Can low-fusing glass application affect the marginal misfit and bond strength of Y-TZP crowns?
}

\section{Monize Carelli Felipe ANTUNES(a) Jean Soares MIRANDA ${ }^{(b)}$ \\ Ronaldo Luís Almeida de CARVALHO(b) \\ Rodrigo Furtado de CARVALHO(a) Estevão Tomomitsu KIMPARA(b) Rodrigo Othávio de ASSUNÇÃO E SOUZA(c) \\ Fabíola Pessôa Pereira LEITE(a)}

(a) Universidade Federal de Juiz de ForaUFJF, Department of Restorative Dentistry, Juiz de Fora, MG, Brazil.

(b) Universidade Estadual Paulista - Unesp, Institute of Science and Technology, São José dos Campos Dental School, São José dos Campos, SP, Brazil.

(c) Universidade Federal do Rio Grande do Norte - UFRN, Prosthodontics Unit, Department of Dentistry, Natal, RN, Brazil.

Declaration of Interest: The authors certify that they have no commercial or associative interest that represents a conflict of interest in connection with the manuscript.

Corresponding author: Jean Soares Miranda, PhD Student E-mail: jeansoares@msn.com

https://doi.org/10.1590/1807-3107bor-2018.vol32.0034

Submitted: December 04, 2017

Accepted for publication: March 05, 2018

Last revision: March 13, 2018
Abstract: To evaluate the effect of different surface treatments on the marginal misfit and retentive strength between Y-TZP crowns and an epoxy resin. Forty (40) epoxy resin (G10) abutments (height: $5 \mathrm{~mm}$, conicity: 60, finish line: large chamfer) with equal dimensions were milled and included in polyurethane to simulate the periodontal ligament. Next, 40 Y-TZP crowns (thickness: 1mm) were milled (Cerec inLab) and randomly divided into four groups $(n=10)$ according to the surface treatment: GS(glaze spray), GP(glaze powder/liquid), P(zirconia primer) and RS(tribochemical silica coating).The conditioned surfaces were cemented with dual self-adhesive cement, light cured and submitted to thermomechanical cycling $\left(2 \times 106,100 \mathrm{~N}, 4 \mathrm{~Hz}, 5^{\circ} / 55^{\circ} \mathrm{C}\right)$. Marginal misfit was analyzed by a stereomicroscope and SEM. Retentive strength test was performed $(1 \mathrm{~mm} / \mathrm{min})$ until crown debonding. Glaze layer thickness was also performed to GS and GP groups. Marginal misfit data were analyzed by Kruskal Wallis and Dunn tests; one-way ANOVA and Tukey (5\%) analyzed the tensile strength data. The marginal misfit of the GS $(48.6 \pm 19.9 \mu \mathrm{m})$ and GP $(65.4 \pm 42.5 \mu \mathrm{m})$ were statistically lower than the RS $(96 \pm 62.9 \mu \mathrm{m})$ and $\mathrm{P}(156 \pm 113.3 \mu \mathrm{m})(\mathrm{p}=0.001)$.The retentive strength of the GP $(470.5 \pm 104.1 \mathrm{~N})$ and GS $(416.8 \pm 170.2 \mathrm{~N})$ were similar to the P $(342.1 \pm 109.7 \mathrm{~N})$, but statistically higher than those of the RS $(208.9 \pm 110 \mathrm{~N})$. The GS and GP glaze layer was $11.64 \mu \mathrm{m}$ and $9.73 \mu \mathrm{m}$ respectively. Thus, glaze application promoted lower marginal discrepancy and higher retentive strength values than conventional techniques.

Keywords: Biomedical and Dental Materials; Crowns; Ceramics.

\section{Introduction}

An important factor for successful ceramic restorations is a correct cementation protocol. However, the ideal cementation protocol for Y-TZP ceramic crowns is still not well defined, since these ceramics cannot be etched by hydrofluoric acid, as occurs with silica-based ceramics., ${ }^{1,2}$ Therefore, several surface treatments have been proposed to improve bonding between Y-TZP and adhesive cements such as sandblasting with aluminum oxide particles, ${ }^{3,4} \mathrm{Er}: Y A G$ laser irradiation, ${ }^{1,5}$ sandblasting with aluminum oxide particles coated with silica followed by silanization, $2,6,7,8$ use of MDP (methacryloxydecyl dihydrogen phosphate) monomer-based resin cement, ${ }^{5,7,8,9}$ metallic primers, $1,3,4,5,8,9,10,11,12$ selective infiltration, ${ }^{8,13}$ and plasma spraying. ${ }^{7,8}$ 
Another proposed treatment is the vitrification of the Y-TZP surface through the application of a thin layer of glaze on the inner surface of the crown, which can then be etched by hydrofluoric acid and silanized, creating micro retentions and chemical reactivity similar to the union mechanisms of vitreous ceramics. The micromechanical retentions help establishing a strong, stable, and durable bond of the resin cement to the ceramic substrate ${ }^{2,8,13,14,15,16,17}$. In a recent study, Bottino et al. ${ }^{2}$ evaluated the effect of vitrification on shear bond strength between dentine and Y-TZP ceramic, and noted that this surface treatment improved adhesion between zirconia and resin cement. Similarly, Vanderlei et al., ${ }^{18}$ concluded that vitrification significantly improved adhesion between Y-TZP and resin cement.

Although vitrification seems to be an efficient method, ${ }^{16,19,20}$ the influence of this treatment on the marginal misfit of Y-TZP crowns should be investigated. Thus, the purpose of this study was to evaluate the influence of surface treatments on marginal misfit and retentive strength of Y-TZP crowns. The hypotheses tested were that a) vitrification increases the retentive strength of Y-TZP crowns bonded with resin cement; and that b) vitrification increases the marginal discrepancy of these Y-TZP crowns.

\section{Methodology}

The manufacturer, trademark, and batch number of the materials used in this study are listed in Table 1.

\section{Epoxy resin preparations}

An epoxy resin reinforced by glass fiber mesh (NEMA grade G-10, International Paper, Hampton, USA) was used to simulate a natural tooth. This material is considered analogous to dentine. ${ }^{21}$

A 3-D model of a right maxillary second molar with crown and root preparation was constructed in the CAD program (Rhinoceros version 4.0 Robert McNeel and Associates, USA). The coronal part had 5 $\mathrm{mm}$ in height, conicity of $6^{\circ}$ and the preparation was finished in a large chamfer. Next, $20 \mathrm{~mm}$ diameter sticks of NEMA grade G-10 epoxy resin were milled in a specific machine (Romi D600, Santa Bárbara d'Oeste, Brazil) with a $1.5 \mathrm{~mm}$ spherical carbide bur to generate 40 bases with the pre-defined dimensions (Figure 1A). The milling cutter was replaced every ten preparations.

After milling, the G-10 bases were marked $2 \mathrm{~mm}$ below the cement-enamel junction (pre-determined as finishing line of the preparation) using a digital caliper (500, Mitutoyo Sul Americana Ltda, Suzano, $\mathrm{SP}$, Brazil). The root portion was covered with polyether (Impregum Soft, 3M ESPE, Seefeld, Germany) to simulate the periodontal ligament ${ }^{22}$. A uniform coverage of approximately $0.3 \mathrm{~mm}$ was obtained by immersing the root portion in a specific plastic wax (PW 1 Plastic - Kota Imports, São Paulo, SP, Brazil) for two seconds up to the marked distance of $2 \mathrm{~mm}$. The constant flow of the wax was obtained by means of an electric wax heating apparatus (Mega Bell, Cera Matic Júnior, São Paulo, Brazil) with temperature control at $90^{\circ} \mathrm{C}$ confirmed by thermometer.

Table 1. Commercial brand, material type, manufacturer, and batch number of materials used in the research.

\begin{tabular}{lccc}
\hline Commercial brand & Material type & Manufacturer & Batch number \\
\hline IPS e.max ${ }^{\circledR}$ ZirCAD & Y-TZP ceramic & Ivoclar-Vivadent/ Schaan, Liechtenstein & R850002 \\
Rocatec ${ }^{\circledR}$ Soft & Silica-coated alumina & 3M ESPE, St. Paul, Minnesota, USA & 424975 \\
VITA Akzent ${ }^{\circledR}$ Plus & Glaze Spray & Vita Zanhfabrik, Bad Sachingen, Germany & 33301 \\
& & & 21740 \\
Vita Akzent Glaze Fluid & Glaze powder/liquid & Vita Zanhfabrik, Bad Sachingen, Germany & 22601 \\
Signum Zirconia Primer & Zirconia primer & Heraeus Kulzer GmbH, Germany & 10123 \\
Condac Porcelana & 10\% Hydrofluoric acid & Dentsply, Petrópolis, RJ, Brazil & 9630446 \\
Rely X U200 & Self-adhesive resin cement & 3M ESPE, Sumaré, SP, Brazil & 544887 \\
Rely X Ceramic Primer & Silane & 3M ESPE, Sumaré, SP, Brazil & 2721 \\
\hline
\end{tabular}



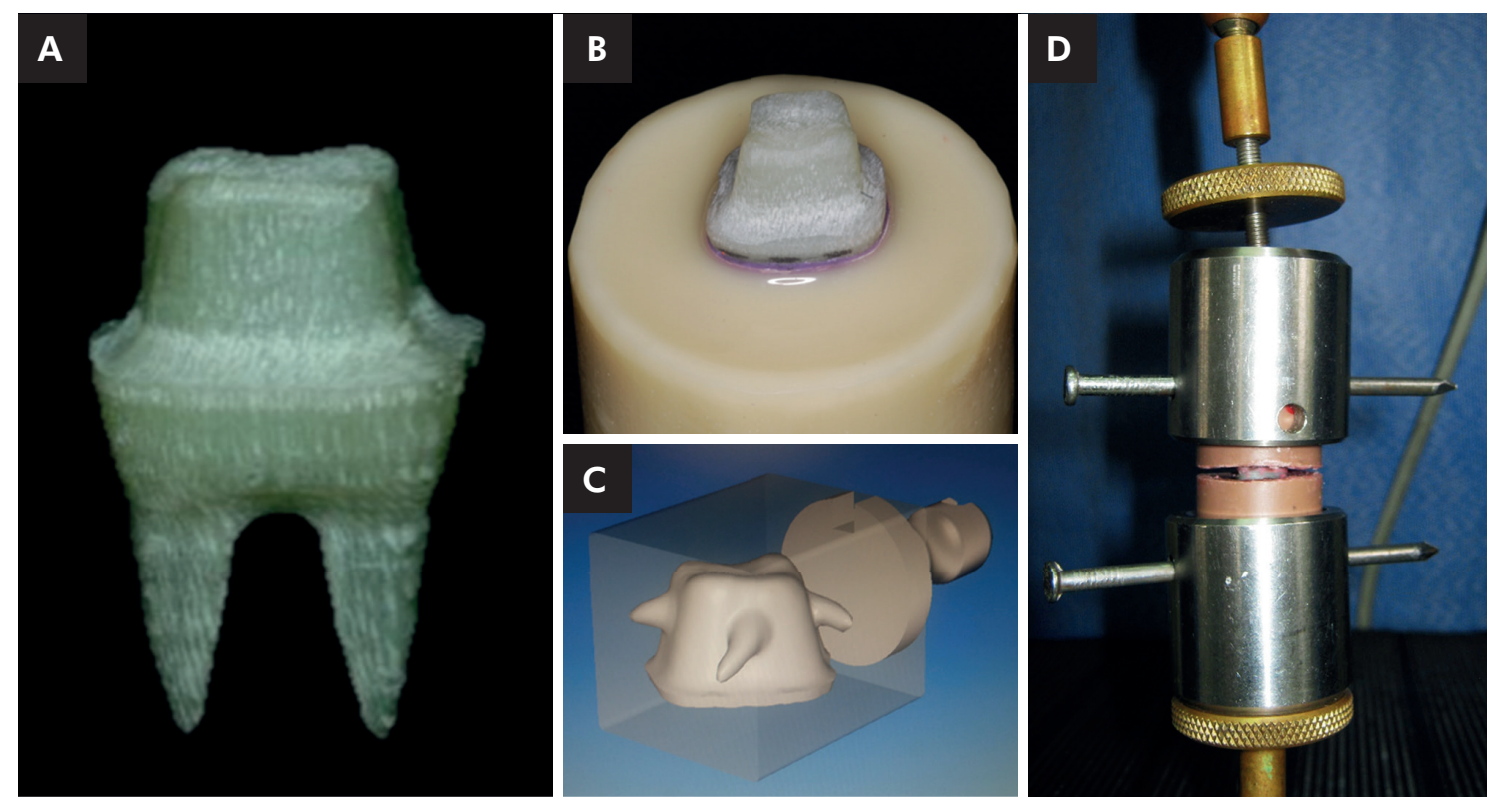

Figure 1. Preparation for total crown in a right maxillary second molar milled in G10 (A). Epoxy resin base was used for periodontal ligament simulation (B). Design of the crown milled by CAD/CAM (C). Sample in the universal test machine for the retentive strength test (D).

Next, G-10 was positioned inside a PVC cylinder matrix with $15 \mathrm{~mm}$ diameter and $20 \mathrm{cmm}$ high. Polyurethane (F16; Axson, Cergy, France) was inserted in this matrix. After polyurethane polymerization, the set was immersed in water at $75^{\circ} \mathrm{C}$ for $1 \mathrm{~min}$ to remove the wax layer and then polyether was applied around the root surface at the cervical level, $2 \mathrm{~mm}$ short of the marked area (Figure 1B). Before cementation, the preparations were cleaned with pumice and water paste, water-sprayed, and air-dried, as recommended by the resin cement manufacturer.

\section{Manufacture of Y-TZP crowns}

The CAD/CAM system (Cerec inLab; Sirona; Bensheim, Germany) was used to manufacture 40 right maxillary second molars Y-TZP (Vita Zahnfabrick, Germany). Crowns were prepared with standardized anatomy and dimensions with $50 \mu \mathrm{m}$ of internal relief. A Step Bur 20 cylindrical diamond bur was used (Sirona; Bensheim, Germany), and the milling cutter was replaced every ten preparations.

The crown design and occlusal anatomy were standardized according to the Cerec program archives. The dimensions of all crowns were standardized by epoxy resin bases. Small "hooks" were placed on the buccal, lingual, distal, and mesial areas of the crown surfaces to prevent debonding from the inclusion material during the retentive strength test (Figure 1C). Afterwards, the integrity of the crowns was evaluated by stereomicroscope (Discovery V-20, Zeiss, Germany) at a $40 \times$ magnification and no crown was discarded. The crowns were after sintered in a Zyrcomat T oven (Vita Zahnfabrick, Germany). The integrity of crowns was checked again and the internal relief of one crown from each randomly selected group was evaluated using the replicate technique with a light-weight vinyl polysiloxane/silicone film (Elite HD Light Body, Zhermack, Badia-Polesine, Rovigo, Italy). ${ }^{23}$ The thickness of the film was measured in a stereomicroscope in different areas (Discovery V-20, Zeiss, Germany) at 30× magnification. A uniform $50-\mu \mathrm{m}$ thickness pattern obtained from the internal relief was observed for all experimental groups. Random Allocation Software (Isfahan University of Medical Sciences, Isfahan, Iran) was used to allocate the samples among the groups.

\section{Surface treatments and crown luting}

The crowns were cleaned by ultrasound (Ultrasonic Washing Machine, Cristófoli, Campos Mourão, Brazil) with distilled water for $5 \mathrm{~min}$ and randomly assigned to four groups $(n=10)$ according to surface treatment: 
RS - sandblasting with silica-coated alumina (Rocatec Soft, 3M ESPE, St. Paul, Minnesota, USA), GS - glaze spray application (Glaze Spray Vita Akzent Plus (Vita Zanhfabrik, Bad Sachingen, Germany), GP - glaze powder/liquid application (Glaze Powder/Liquid Vita Akzent Plus, Vita Zanhfabrik, Bad Sachingen, Germany), and P - zirconia primer (Signum Zirconia Bond, Heraeus Kulzer, Germany).

The RS group had the internal surfaces sandblasted using a specific apparatus (Dento-PrepTM, RØNVIG A/S) with 30- $\mu \mathrm{m}$ silica-coated alumina particles. The pressure exerted was 2.8 bar for $15 \mathrm{~s}$ at a $10 \mathrm{~mm}$ distance between the surface and the apparatus tip. Then, silane RelyX Ceramic Primer (3M ESPE, St. Paul, Minnesota, USA) was actively applied with a microbrush onto the crown, and left for 60 seconds.

In the GS group, the glaze spray was applied for two seconds at a 5-mm standard distance of the ceramic's inner surface. Then, the samples were taken to a VITA VACUMAT 6000 MP oven (VITA, Zahnfabrik, Germany) for the glaze firing process. Soon after, the crown was etched with $10 \%$ HF for $60 \mathrm{~s}$, washed with air-water spray for $15 \mathrm{~s}$, dried and then RelyX Ceramic Primer was applied.

In the GP group, the cement surface was treated with Powder/Liquid Glaze in the correct proportion ( $0.2 \mathrm{~g}$ of powder to 8 drops of liquid). A single layer was applied to the inner surface of the Y-TZP crown with a thin brush, and then taken to the oven for glaze firing. The HF etching and the silane application was done the same way as for the GS group.

In the P group, a Signum Zirconia Bond I + II layer primer was applied. The excess was removed with air jets and the surface was light cured for $90 \mathrm{~s}$ with $1200 \mathrm{Wm} / \mathrm{cm}^{2}$ LED (Radii Cal, SDI, Australia).

Luting of the crowns was performed with RelyX U200 self-adhesive resin cement (3M ESPE, St. Paul, Minnesota, USA) applied to the inner surface of the treated crowns. After adaptation to the G10 preparation, a 750-g controlled pressure was exerted onto the crown. The cement excess was removed with a microbrush and each face of the crown was light cured for $20 \mathrm{~s}$ with $1200 \mathrm{~mW} / \mathrm{cm}^{2}$ LED (Radii Cal, SDI, Australia). The light intensity was measured on a radiometer (Kondortech-Kondentech, São Paulo, Brazil).

\section{Thermomechanical cycling}

A total of $2 \times 10^{6}$ thermomechanical cycles were performed in the ERIOS Cycler (ERIOS Cycler ER 37000, Paraná, Brazil) with $100 \mathrm{~N}$ load, $4 \mathrm{~Hz}$ frequency and a $4 \mathrm{~mm}$ stainless steel piston. The piston touched the internal inclines of the buccal and lingual cusps of the Y-TZP crown's occlusal surface, establishing a 3 -point contact. During the test, all samples reached a thermal equilibrium between $5^{\circ}$ and $55^{\circ} \mathrm{C}$ with 60-s duration of each cycle, and a 30-s intermediate pause maintained by a thermostatic controller, which totaled 5555 thermal cycles for each group.

\section{Marginal Misfit Analysis}

After the thermomechanical cycling, the samples were evaluated by stereomicroscope (Discovery V-20, Zeiss, Germany) at $40 \times$ magnification to observe the crown's marginal misfit. The measure was obtained from the end of the preparation to the margin of the crown. Eight measurements (mesiobuccal, buccal, distobuccal, distal, distopalatine, palatine, mesiopalatine and mesial) were performed perpendicular to each crown using a ruler coupled to the stereomicroscope software (AxioVision Rel 4.8, Zeiss, Germany). The mean of the eight measurements was used for statistical analysis. Scanning electron microscopic (SEM) examination under high-resolution close-ups (Inspect S50, FEI Company, Eindhoven, Netherlands; 1000×) was also conducted.

Glaze layer thickness measurement

Glaze layer thickness was measured on the GS and GP additional crowns after the HF etching. Crowns were then mesiodistally cut in an IsoMet 1000 Precision Saw (Buehler, Lake Buff-IL, USA) and cleaned in a distilled water sonic bath for $5 \mathrm{~min}$. The surfaces were then sputtered for SEM analysis at $1000 \times$ magnification. Measurements were performed in the cervical, axial, and occlusal regions. The mean of these three measurements was calculated to obtain the glaze thickness result.

\section{Retentive strength test}

The root portion of the NEMA grade G-10 was removed from the polyurethane and included in chemically activated acrylic resin (JET, Campo Limpo Paulista, Brazil). After resin polymerization, 
the entire crown/G-10 interface was protected with wax (NeWWax, Quintino, Brazil) and the Y-TZP crowns were embedded in the same resin. After resin polymerization, the wax was removed and the sample was mounted on a universal testing machine (EMIC DLM 1000 - São José dos Pinhais, Brazil). All samples were submitted to the retentive strength test using a 1000-Kgf load cell at a speed of $1 \mathrm{~mm} / \mathrm{min}$ (Figure 1D).

\section{Failure analysis}

A failure analysis was conducted in three steps as follows: examination of the crowns and of the G10 specimens under stereomicroscope at 50× magnification (Discovery Z-20, Zeiss, Jena, Germany) for failure classification (adhesive or cohesive) and selection of significant specimens for further SEM investigation. The chosen crowns were cut in the lingual-buccal direction and mounted on aluminum stubs; SEM examination under high-resolution magnification was conducted to observe the presence of cement on the zirconia crown and the substrate.

\section{Statistical Analysis}

For the marginal mismatch analysis, the data were submitted to the Kruskal-Wallis test and the Dunn's test. One-way ANOVA and Tukey's test were used for the retentive strength analysis. The significance level considered for all tests was $5 \%$.

\section{Results}

\section{Marginal misfit}

The Kruskal-Wallis ( $p=0.001)$ and the Dunn's test $(p=0.0005)$ indicated that the marginal misfit of the GS and GP groups were statistically lower than the RS and Pgroups (Table 2). The P group had statistically higher values than all the other groups (Figure 2).

\section{Glaze layer thickness}

A glaze layer thickness of $11.64 \mu \mathrm{m}$ was observed in the sectioned extra GS crowns, and a thinner layer of $9.73 \mu \mathrm{m}$ in the GP sample (Figure 3).

\section{Retentive strength test}

One-way ANOVA revealed a significant interaction $(p=0.001)$, indicating that bond strength was dependent on surface treatment. The retentive strength values of the GP and GS groups were similar and statistically higher than the RS group. The P group was statistically similar to the others (Table 2).

\section{Failure analysis}

The failures observed through stereomicroscopy were predominantly adhesive. The images reinforced that the resin cement remained adhered in the internal structure of the Y-TZP crowns of all groups (Figure 4).

\section{Discussion}

The difficulty of bonding the Y-TZP to the resin cement is reported as one of the main limitations for the use of this type of ceramic. ${ }^{1,2,24}$ To evaluate the retentive strength of Y-TZP ceramics to resin cements, this study treated the Y-TZP crowns inner surface with four different surface treatments: sandblasting with silica-coated alumina, application of a zirconia primer with MDP, and application of a glaze layer by two different vitrification methods. The marginal discrepancies were also measured for each of these treatments, since the application of the glaze layer has been indicated as the cause of marginal mismatches. ${ }^{8}$

Table 2. Tukey's test results for tensile strength ( $\mathrm{n}$ ) and ANOVA for marginal misfit ( $\mu \mathrm{m})$.

\begin{tabular}{lccc}
\hline Groups & $\mathrm{n}$ & Shear Strength \pm SD $(\mathrm{N})$ & Marginal mismatch \pm SD $(\mu \mathrm{m})$ \\
\hline Glaze (powder/liquid) & 10 & $470.5 \pm 104.1^{\mathrm{a}}$ & $48.6 \pm 19.9^{\mathrm{a}}$ \\
Glaze (Spray) & 10 & $416.8 \pm 170.2^{\mathrm{a}}$ & $654^{4} \pm 42.5^{\mathrm{a}}$ \\
Primer & 10 & $342.1 \pm 109.7^{\mathrm{ab}}$ & $156 \pm 113.3^{\mathrm{b}}$ \\
Rocatec & 10 & $208.9 \pm 110.0^{\mathrm{b}}$ & $96 \pm 62.9 \mathrm{c}$ \\
\hline
\end{tabular}

Different letters indicate significant statistical differences. 

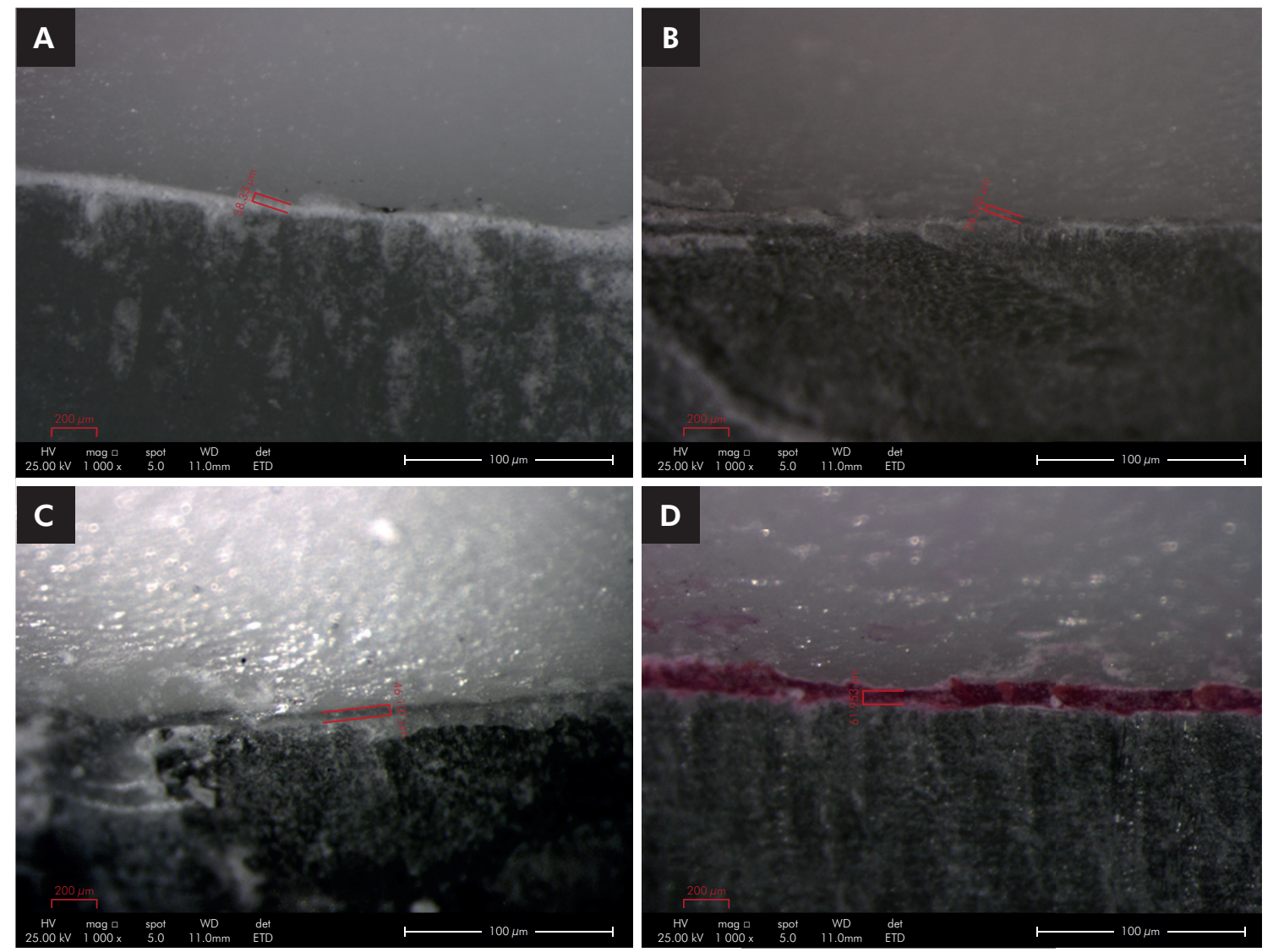

Figure 2. SEM images $(40 \times)$ of the vestibular marginal discrepancy of GS (a), GP (b), RS (c) and P (d) groups after luting with resin cement. Smaller dimensions of marginal mismatch occurred in the groups in which a glaze layer was applied to the Y-TZP crowns inner surface.
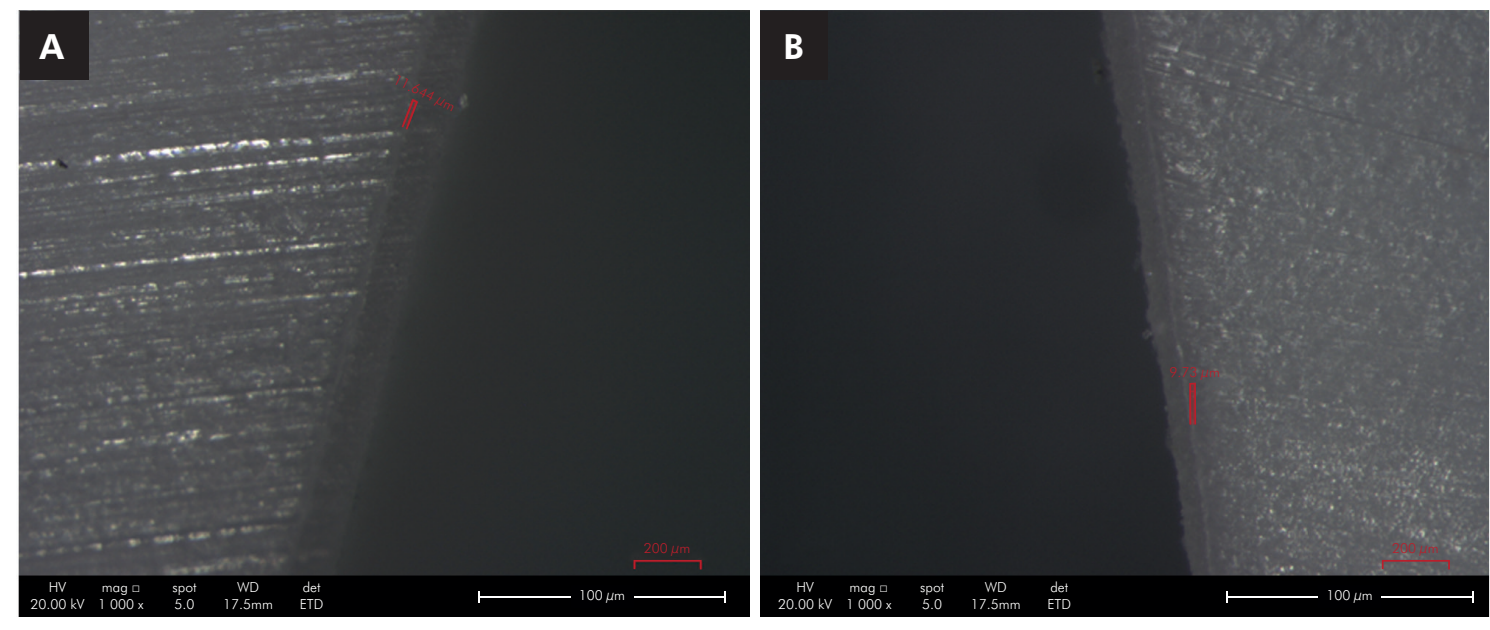

Figure 3. a) Glaze layer thickness of the GS group (1 $1.64 \mu \mathrm{m})$ and b) the GP group ( $9.73 \mu \mathrm{m})$ observed in SEM using $1000 \times$ magnification.

Ideally, under laboratory conditions, the material used as a substrate for crown luting should have an elastic behavior similar to human dentine. Kelly et al. ${ }^{21}$ evaluated the retentive strength of human dentine and a woven glass fiber-filled epoxy material (NEMA G10), obtaining reasonable results and suggesting that they have similar elastic modules and bond strength to the composite resin. This epoxy resin also showed adhesive 

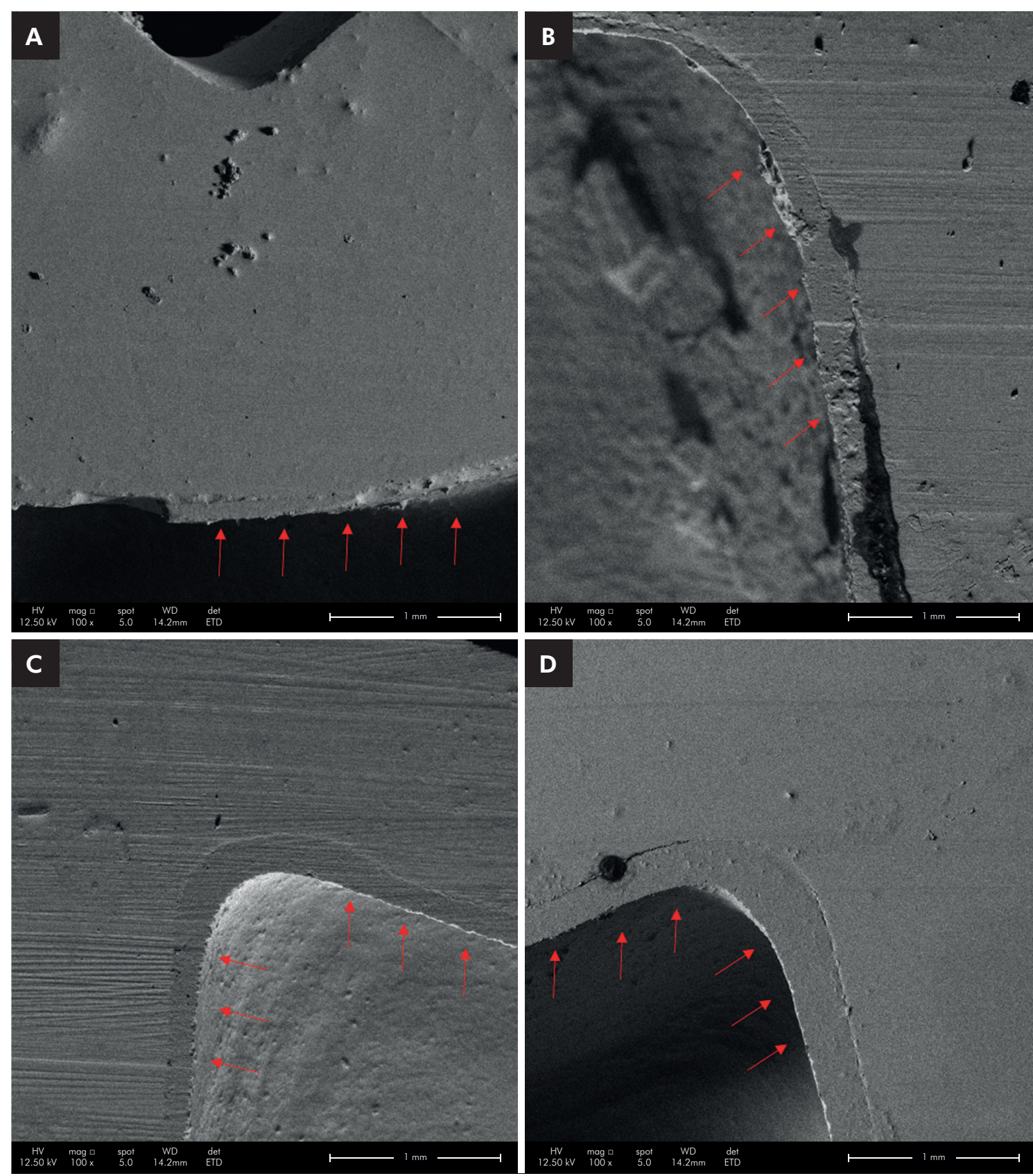

Figure 4. Micrographs showing the presence of cement on the inner surface of the Y-TZP crowns (indicated by arrows), which characterizes adhesive failures of the cement with the preparation on epoxy resin. Groups GP (A), GS (B), RS (C) and P (D).

properties ${ }^{21,25,26}$ and is currently considered a material similar to dentine, been used as a reliable substrate in some laboratory studies ${ }^{27,28}$. Standardization of the substrate is crucial to verify the pretreatment factor alone in zirconia crowns. ${ }^{20}$ To avoid possible debonding, cracking, and fracture of the covering ceramics crowns, ${ }^{29,30}$ the present study used monolithic Y-TZP crowns.
The two methods of glaze application differ by product presentation; one is a spray (GS) and the other has a powder and a liquid component (GP). This study evaluated which method is more viable and effective. It was observed that the GP and GS presented statistically similar retentive strength values between each other and the $\mathrm{P}$ group, but the bond 
strength value of the vitrified groups was statistically superior to the RS. This data are similar to those found by Vanderlei et al., ${ }^{18}$ which state that the application of low-fusing glass on the surface of Y-TZP followed by hydrofluoric acid etching and silanization significantly improved the bond between Y-TZP and resin cement.

Therefore, regardless of the application method, these two vitrification technics were effective, thus corroborating the literature ${ }^{18}$ and leading to the acceptance of the first hypothesis. The glaze application on the Y-TZP crowns created a thin glass layer on the inner surface of this ceramic, allowing the hydrofluoric acid to create microretentions in the surface and facilitating the penetration of the luting agent. ${ }^{2,13,14,15,16,17}$ Previous studies ${ }^{17,18,31,32,33}$ that used tensile and shear bond strength tests reported that the application of a thin layer of low-fusing porcelain glaze on the zirconia surface followed by HF etching generated similar or higher adhesion values compared with conventional surface-treatment methods. This was correlated to a better chemical interaction mediated by the silane application process on the Y-TZP vitrified inner surface. ${ }^{2,9,10,18}$

The lower results of the RS group are also due to the questionable stability of sandblasting bonding over time, because hydrolytic degradation occurs together with aging and causes the silica particles to peel off the Y-TZP, causing infiltration and detachment of the crowns. ${ }^{33}$ The thermomechanical cycling laboratorial aging was employed based on studies described in the literature ${ }^{34,35}$ showing that applying thermal stress alone does not lead to clinically relevant deterioration. ${ }^{36}$ In addition, thermomechanical cycling was reported ${ }^{34}$ as being responsible for decreasing by $80 \%$ the fracture resistance of posterior crowns luted with resin cements. In the present study, the authors used $2 \times 10^{6}$ cycles aiming to simulate a long aging period, which corresponds to 10 years of mouth functioning on average. ${ }^{36,37,38}$ However, the RS group achieved a retentive strength similar to the P group. This finding corroborates the literature, ${ }^{12,39,40}$

Although the zirconia crowns were manufactured with similar internal relief, the marginal misfit was different among the groups with different surface treatments. Contrary to some previous research ${ }^{4,18}$ that states that the glaze on the inner surface of Y-TZP crowns may affect their adaptation, the GS
$(48.69 \pm 19.90 \mu \mathrm{m})$ and GP $(65.48 \pm 42.57 \mu \mathrm{m})$ groups presented the lowest marginal misfit, and were statistically similar between them, thus rejecting the second hypothesis. The misfit values of our research were still higher than those found by Bottino et al. ${ }^{2}$ $(12 \mu \mathrm{m})^{2}$ and Ntala et al. ${ }^{17}(31.8 \mu \mathrm{m})$, however the clinically recommended maximum misfit is around $120 \mu \mathrm{m},{ }^{2,18}$ so the low-fusing glass application is not capable of causing significant marginal damages in the Y-TZP restorations. ${ }^{32}$ In group $\mathrm{P}$, the misfit value was higher than that considered acceptable $(156 \pm 113.3 \mu \mathrm{m})$. This probably occurred because this primer requires a light cure prior to the resin cement insertion and this additional stage may have favored the formation of a first layer that did not exist in the other groups in this study.

The present study had some limitations. It is difficult to compare our results with the current literature because most studies did not use crown specimens with dental preparation., ${ }^{9,41,42}$ Maybe the restoration shape in crowns favored the maintenance of the cement on the zirconia crown. However, even though the epoxy resin used has some similarities to dentine, it cannot be directly compared to the complex bond procedure. Thus, caution should be taken in extrapolating the results to a clinical situation. Nevertheless, considering the results obtained in the retentive test and the presence of cement on the crown's inner surface, it is believed that the inner glaze application techniques can solve the Y-TZP luting problem, since it is a simple and affordable method, and the material used is readily available. With this technique, the clinician can receive from the prosthodontic lab a zirconia crown with an etchable intaglio surface. However, additional studies should be conducted to confirm the stability and durability of the bond in order to assess the time of hydrofluoric acid conditioning; follow-up studies are also needed.

\section{Conclusion}

Within the limitations of this study, it can be concluded that glaze application in the inner surface of the Y-TZP crowns promoted lower marginal discrepancy values and higher retentive strength data compared to the conventional techniques. 


\section{References}

1. Dias de Souza GM, Thompson VP, Braga RR. Effect of metal primers on microtensile bond strength between zirconia and resin cements. J Prosthet Dent. 2011 May;105(5):296-303. https://doi.org/10.1016/S0022-3913(11)60055-3

2. Bottino MA, Bergoli C, Lima EG, Marocho SM, Souza $R O$, Valandro LF. Bonding of Y-TZP to dentin: effects of Y-TZP surface conditioning, resin cement type, and aging. Oper Dent. 2014 May-Jun;39(3):291-300. https://doi.org/10.2341/12-235-L

3. Maeda FA, Bello-Silva MS, Eduardo CP, Miranda Junior WG, Cesar PF. Association of different primers and resin cements for adhesive bonding to zirconia ceramics. J Adhes Dent. 2014 Jun;16(3):261-5. https://doi.org/10.3290/i.jad.a31938

4. Pereira LL, Campos F, Dal Piva AM, Gondim LD, Souza RO, Özcan M. Can application of universal primers alone be a substitute for airborne-particle abrasion to improve adhesion of resin cement to zirconia? J Adhes Dent. 2015 Apr;17(2):169-74. https://doi.org/10.3290/i.jad.a33974

5. Barbosa WF, Di Francescantonio M, Aguiar TR, Cavalcanti AN, Oliveira MT, Giannini M. [Effect of application of metal primers on the bond strength of resin cements to zirconia]. RPG. Rev Pós Grad. 2011;18(4):224-8. Portuguese.

6. Cavalcanti AN, Foxton RM, Watson TF, Oliveira MT, Giannini M, Marchi GM. Y-TZP ceramics: key concepts for clinical application. Oper Dent. 2009 May-Jun;34(3):344-51. https:// doi.org/10.2341/08-79

7. Papia E, Larsson C, Toit M, Vult von Steyern P. Bonding between oxide ceramics and adhesive cement systems: a systematic review. J Biomed Mater Res B Appl Biomater. 2014 Feb;102(2):395-413. https://doi.org/10.1002/jbm.b.33013

8. Melo RM, Souza RO, Dursun E, Monteiro EB, Valandro $L F$, Bottino MA. Surface treatments of zirconia to enhance bonding durability. Oper Dent. 2015 Nov-Dec;40(6):636-43. https://doi.org/10.2341/14-144-L

9. Amaral M, Belli R, Cesar PF, Valandro LF, Petschelt A, Lohbaver $U$. The potential of novel primers and universal adhesives to bond to zirconia. J Dent. 2014 Jan;42(1):90-8. https://doi.org/10.1016/i.jdent.2013.11.004

10. Cura C, Özcan M, Isik G, Saracoglu A. Comparison of alternative adhesive cementation concepts for zirconia ceramic: glaze layer vs zirconia primer. J Adhes Dent. 2012 Feb;14(1):75-82. https://doi.org/10.3290/i.jad.a21493

11. Giannini M, Dias TM, Pacheco RR, Sá RB, Di Francescantonio $M$, Berger SB. [Evaluation of the effect of metal primers and type of resin cement on the bond strength to zirconia]. Rev Bras Odontol. 2012 jan/jun;69(1):15-20. Portuguese.

12. Han IH, Kang DW, Chung CH, Choe HC, Son MK. Effect of various intraoral repair systems on the shear bond strength of composite resin to zirconia. J Adv Prosthodont. 2013 Aug;5(3):248-55. https://doi.org/10.4047/jap.2013.5.3.248
13. Aboushelib MN, Kleverlaan CJ, Feilzer AJ. Selective infiltration-etching technique for a strong and durable bond of resin cements to zirconia-based materials. J Prosthet Dent. 2007 Nov;98(5):379-88. https://doi.org/10.1016/S0022-3913(07)60123-1

14. Aboushelib MN, Feilzer AJ, Kleverlaan CJ. Bonding to zirconia using a new surface treatment. J Prosthodont. 2010 Jul;19(5):3406. https://doi.org/10.1111/i.1532-849X.2010.00575.x

15. Aboushelib MN. Evaluation of zirconia/resin bond strength and interface quality using a new technique. J Adhes Dent. 2011 Jun;13(3):255-60. https://doi.org/10.3290/i.jad.a19241

16. Kitayama S, Nikaido T, Maruoka R, Zhu L, Ikeda M, Watanabe $A$ et al. Effect of an internal coating technique on tensile bond strengths of resin cements to zirconia ceramics. Dent Mater J. 2009 Jul;28(4):446-53. https://doi.org/10.4012/dmj.28.446

17. Ntala P, Chen X, Niggli J, Cattell M. Development and testing of multi-phase glazes for adhesive bonding to zirconia substrates. J Dent. 2010 Oct;38(10):773-81. https://doi.org/10.1016/i.jdent.2010.06.008

18. Vanderlei A, Bottino MA, Valandro LF. Evaluation of resin bond strength to yttria-stabilized tetragonal zirconia and framework marginal fit: comparison of different surface conditionings. Oper Dent. 2014 Jan-Feb;39(1):50-63. https://doi.org/10.2341/12-269-L

19. Derand T, Molin M, Kvam K. Bond strength of composite luting cement to zirconia ceramic surfaces. Dent Mater. 2005 Dec;21(12):1158-62. https://doi.org/10.1016/i. dental.2005.02.005

20. Yildiz C, Vanlioğlu BA, Evren B, Uludamar A, Ozkan YK. Marginal-internal adaptation and fracture resistance of CAD/ CAM crown restorations. Dent Mater J. 2013;32(1):42-7. https://doi.org/10.4012/dmj.2012-148

21. Kelly JR, Rungruanganunt P, Hunter B, Vailati F. Development of a clinically validated bulk failure test for ceramic crowns. J Prosthet Dent. 2010 Oct;104(4):228-38. https://doi.org/10.1016/S0022-3913(10)60129-1

22. Brosh T, Zary R, Pilo R, Gavish A. Influence of periodontal ligament simulation and splints on strains developing at the cervical area of a tooth crown. Eur J Oral Sci. 2012 Oct;120(5):466-71. https://doi.org/10.1111/j.1600-0722.2012.00990.x

23. Bottino MA, Campos F, Ramos NC, Rippe MP, Valandro LF, Melo RM. Inlays made from a hybrid material: adaptation and bond strengths. Oper Dent. 2015 May-Jun;40(3):E83-91. https://doi.org/10.2341/13-343-L

24. Wandscher VF, Prochnow C, Rippe MP, Dorneles LS, Callegari GL, Baldissara P et al. Retentive Strength of Y-TZP Crowns: Comparison of Different Silica Coating Methods on the Intaglio Surfaces. Oper Dent. 2017 Sep/Oct;42(5):E121-33. https://doi.org/10.2341/16-090-L 
- Can low-fusing glass application affect the marginal misfit and bond strength of Y-TZP crowns?

25. May LG, Kelly JR, Bottino MA, Hill T. Effects of cement thickness and bonding on the failure loads of CAD/

CAM ceramic crowns: multi-physics FEA modeling and monotonic testing. Dent Mater. 2012 Aug;28(8):e99-109. https://doi.org/10.1016/i.dental.2012.04.033

26. Corazza PH, Feitosa SA, Borges AL, Della Bona A. Influence of convergence angle of tooth preparation on the fracture resistance of Y-TZP-based all-ceramic restorations. Dent Mater. 2013 Mar;29(3):339-47. https://doi.org/10.1016/i.dental.2012.12.007

27. Alessandretti R, Borba M, Benetti P, Corazza PH, Ribeiro $R$, Della Bona A. Reliability and mode of failure of bonded monolithic and multilayer ceramics. Dent Mater. 2017 Feb;33(2):191-7. https://doi.org/10.1016/i.dental.2016.11.014

28. Gressler May L, Kelly JR, Bottino MA, Hill T. Influence of the resin cement thickness on the fatigue failure loads of CAD/ CAM feldspathic crowns. Dent Mater. 2015 Aug;31(8):895-900. https://doi.org/10.1016/i.dental.2015.04.019

29. Bever F, Stimmelmayr M, Gueth JF, Edelhoff D, Naumann M. In vitro performance of full-contour zirconia single crowns. Dent Mater. 2012 Apr;28(4):449-56. https://doi.org/10.1016/i.dental.2011.11.024

30. Zesewitz TF, Knauber AW, Nothdurft FP. Fracture resistance of a selection of full-contour all-ceramic crowns: an in vitro study. Int J Prosthodont. 2014 May-Jun;27(3):264-6. https://doi.org/10.11607/ijp.3815

31. Baldissara P, Querzè M, Monaco C, Scotti R, Fonseca RG. Efficacy of surface treatments on the bond strength of resin cements to two brands of zirconia ceramic. J Adhes Dent. 2013 Jun;15(3):259-67. https://doi.org/10.3290/i.jad.a28729

32. Valentino TA, Borges GA, Borges LH, Platt JA, CorrerSobrinho L. Influence of glazed zirconia on dual-cure luting agent bond strength. Oper Dent. 2012 Mar-Apr;37(2):181-7. https://doi.org/10.2341/10-220-L P

33. Kern M, Wegner SM. Bonding to zirconia ceramic: adhesion methods and their durability. Dent Mater. 1998 Jan;14(1):64-71. https://doi.org/10.1016/S0109-5641(98)00011-6
34. Komine F, Tomic M, Gerds T, Strub JR. Influence of different adhesive resin cements on the fracture strength of aluminum oxide ceramic posterior crowns. J Prosthet Dent. 2004 Oct;92(4):35964. https://doi.org/10.1016/i.prosdent.2004.07.018

35. Rosentritt M, Plein T, Kolbeck C, Behr M, Handel G. In vitro fracture force and marginal adaptation of ceramic crowns fixed on natural and artificial teeth. Int J Prosthodont. 2000 Sep-Oct;13(5):387-91.

36. Heintze SD, Faouzi M, Rousson V, Ozcan M. Correlation of wear in vivo and six laboratory wear methods. Dent Mater. 2012 Sep;28(9):961-73. https://doi.org/10.1016/i.dental.2012.04.006

37. Borba M, de Araújo MD, Fukushima KA, Yoshimura HN, Griggs JA, Della Bona Á et al. Effect of different aging methods on the mechanical behavior of multi-layered ceramic structures. Dent Mater. 2016 Dec;32(12):1536-42. https://doi.org/10.1016/i.dental.2016.09.005

38. Daneshkazemi AR, Davari AR, Ataei E, Dastjerdi F, Haiighasemi E. Effects of mechanical and thermal load cycling on micro tensile bond strength of clearfil SE bond to superficial dentin. Dent Res J (Isfahan). 2013 Mar; 10(2):202-9. https://doi.org/10.4103/1735-3327.113344

39. Stefani A, Brito RB Jr, Kina S, Andrade OS, Ambrosano GM, Carvalho AA et al. Bond Strength of Resin Cements to Zirconia Ceramic Using Adhesive Primers. J Prosthodont. 2016 Jul;25(5):380-5. https://doi.org/10.1111/jopr.12334 P

40. Blatz MB, Alvarez M, Sawyer K, Brindis M. How to Bond Zirconia: the APC Concept. Compend Contin Educ Dent. 2016 Oct;37(9):611-7.

41. Tanış MÇ, Akay C, Karakış D. Resin cementation of zirconia ceramics with different bonding agents. Biotechnol Biotechnol Equip. 2015 Mar;29(2):363-7. https://doi.org/10.1080/13102818.2014.996606

42. Sarmento HR, Campos F, Sousa RS, Machado JP, Souza RO, Bottino MA et al. Influence of air-particle deposition protocols on the surface topography and adhesion of resin cement to zirconia. Acta Odontol Scand. 2014 Jul;72(5):346-53. https://doi.org/10.3109/00016357.2013.837958 